\section{A genetic metasomatic link between eclogitic and peridotitic diamond inclusions}

\author{
MICHELE RINALDI ${ }^{1}$, SAMI MIKHAIL ${ }^{1}$, ELEANOR ROSE \\ MARE $^{1}$ AND DIMITRI SVERJENSKY ${ }^{2}$ \\ ${ }^{1}$ University of St Andrews \\ ${ }^{2}$ Johns Hopkins University \\ Presenting Author:mr267@st-andrews.ac.uk
}

Diamond inclusions sample the otherwise inaccessible archive of Earth's deep interior. The geochemical and petrological diversity of diamond inclusions reflects either pre-metasomatic upper mantle heterogeneity or metasomatism coeval with diamond formation. Diamond-hosted mineral inclusions are diverse, including, but not limited to, sulphides, silicates, oxides, carbonates, and metallic phases and several of these mineral families can be sub-divided into three groups, termed inclusion paragenesis. These are [1] peridotitic (i.e. Cr-rich pyrope, diopside, enstatite, olivine), [2] eclogitic (i.e. Cr-poor pyropealmandine, Na-rich clinopyroxene) and [3] websteritic (intermediate compositions). The assignment of inclusion paragenesis is an empirical and subjective classification scheme which does not inform on process, sensu stricto.

We focus on the origin of lithospheric garnet and clinopyroxene inclusions by simulating metasomatic reactions between eclogitic fluids and mantle peridotites at $5 \mathrm{GPa}, 1000^{\circ} \mathrm{C}$, and across a range of redox conditions $\left(\log f \mathrm{O}_{2}=-1\right.$ to $\left.-5 \Delta \mathrm{FMQ}\right)$. Our results demonstrate that fluid-rock interaction can result in the formation of eclogitic, websteritic, and peridotitic silicates from a single fluid during a single diamond-forming metasomatic event (Fig. 1), providing a simple mechanistic explanation for the situation where individual natural diamonds host disequilibrium inclusion assemblages, such as diamonds hosting inclusions of mixed parageneses. Ergo, the petrogenesis of diamond and their inclusions can be syngenetic, and the petrological diversity of diamond inclusions can reflect metasomatism coeval with diamond formation. Our data also show that diamond formation is feasible without the need for any shift in redox or $\mathrm{pH}$ of the fluid and demonstrate that a thermal gradient is not required. Furthermore, during the metasomatism, refractory peridotite can be converted to fertile websterite which could become a pyroxenitic mantle source for oceanic basalts (see Mikhail et al., 2021).

\section{References Cited}

Mikhail, S., Rinaldi, M., Mare, E.R., Sverjensky, D.A. 2021 A genetic link between eclogitic and peridotitic diamond inclusion - Geochemical Perspectives Letters

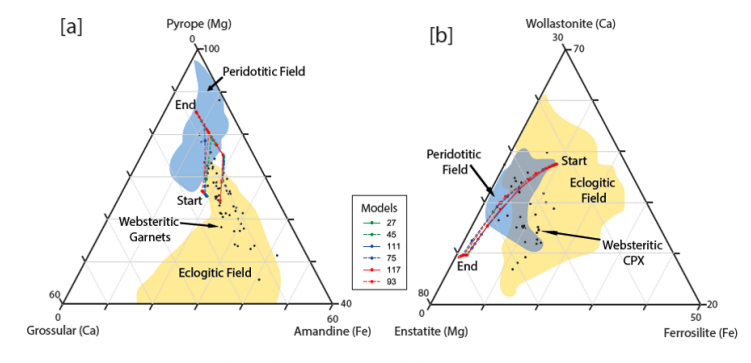

Fig. 1 - Selected model results for predicted [a] garnet and [b] clinopyroxene compositions during progtessive metasomatism. Each model tun refers to a single peridotite metasomatized by a single eclogitic fluid. For more
information, see Mikhail et al., 2021. 